\title{
LATE SURFACTANT THERAPY FOR POSTSURFACTANT SLUMP IN EXTREMELY LOW BIRTH WEIGHT INFANTS
}

\author{
A. Grison, L. Tomasi, M. Zambolin, I. Boscolo, S. Bonato, V. Carlini, R. Golin, S. Nicolussi, C. Panizzolo, \\ L. Vecchiato \\ NICU, San Bortolo Hospital, Vicenza, Italy
}

\begin{abstract}
Aim: To evaluate late suine surfactant therapy for the pulmonary disease in extremely low birth weight infants (ELBW).

Methods: A retrospective study of all ELBW admitted in the NICU of Vicenza during 2007-2009. Patients were divided into three groups: early surfactant for respiratory distress syndrome (Group 1), late surfactant for postsurfactant slump (respiratory failure after six days of life) (Group 2) and no surfactant (Group 3). A respiratory severity score (RSS) was used to measure the severity of lung disease and response to surfactant therapy. In group 2 ventilatory parameters before, after 12 and 24 hours the administration of late surfactant were also evaluated.
\end{abstract}

Results: Over three years, 58 ELBW were analyzed, 36 of group 1, 14 of group 2 and 8 of group 3. Patients of group 2 had lower gestational age and birth weights compared to patients of group 1 and 3 (EGA $25+/-$ 1.27 in group 2 vs 26 +/- 1.92 and 30 +/- 3.06; birth weight 670 grams +/- 155 vs 732 +/- 136 and 884 +/104). More prenatal steroids were used in group 1 than in group 2 (72\% vs 57\%). Patients of group 2 had an improvement of their lung disease showed by a reduction of their RSS for 48 hours. PCO2, pH, MAP improved at both 12 and 24 hours after surfactant administration.

Conclusions: Late surfactant therapy led to a short-term improvement of lung disease in ELBW with postsurfactant slump. These patients were more premature and with lower birth weight. 